\title{
Results of extracorporeal shock wave lithotripsy of gall bladder stones in 693 patients: a plea for restriction to solitary radiolucent stones
}

\author{
A Elewaut, A Crape, M Afschrift, W Pauwels, M De Vos, F Barbier
}

\begin{abstract}
During a period of 24 months 693 consecutive patients with symptomatic gall bladder stones (526 males, 167 females; mean age 51 years, range 18-89) were treated by extracorporeal shock wave lithotripsy with a Piezolith 2300 . The procedure was carried out on an outpatient basis without analgesics or sedatives. Concomitant chemolitholytic treatment (ursodeoxycholic and chenodeoxycholic acid 7.5 $\mathrm{mg} / \mathrm{kg} /$ day each) was administered until three months after total fragment clearance for a maximum therapy period of 1.5 years. In 601 patients with radiolucent stones complete clearance of all fragments was obtained after three, six, 12 , and 18 months in respectively 20 , 41,64 , and $78 \%$. Actuarial analysis of the subgroups according to the stone mass (size and number) selected an ideal patient population with solitary stones less than $20 \mathrm{~mm}$ diameter ( $84 \%$ stone free after one year). The results are significantly less good when the greater the number of stones or their maximal diameter increases. Treatment was interrupted in $3.6 \%$ of the patients. In 90 sludge or fragments remain present. Twenty five patients were lost to follow up for non-biliary reasons. Stone recurrence was $5.7 \%$ at one year and was observed both in patients with solitary and multiple stones. A cost effectiveness analysis suggests that laparoscopic cholecystectomy is the most effective and economic solution, although extracorporeal shock wave lithotripsy for solitary radiolucent stones less than $\mathbf{2 ~ c m}$ is cheaper than conventional cholecystectomy. Extracorporeal shock wave lithotripsy for multiple stones is the most expensive and least effective option.

(Gut 1993; 34: 274-278)
\end{abstract}

University Hospital Gent, Department of Internal Medicine,

Division of

Gastroenterology, Gent, Belgium

A Elewaut

A Crape

M Afschrift

W Pauwels

M De Vos

F Barbier

Correspondence to:

Dr A. Elewaut, University

Hospital Gent, Dept of

Internal Medicine, Division of

Gastroenterology, De

Pintelaan 185, B-9000 Gent,

Belgium.

Accepted for publication

19 June 1992
Since the initial report of the Munich group of treatment of gall bladder stones by extracorporeal shock wave lithotripsy (ESWL), ${ }^{1}$ this treatment has widely captured the attention of the medical literature. ${ }^{2-11}$ Because of the advances in science and technology of lithotripter techniques, it was presented as a simpler alternative to surgery, and the piezoceramic device proved very effective. ${ }^{1213}$ In the mean time laparoscopic cholecystectomy has rapidly become a popular method..$^{1+17}$ The aim of this study is to evaluate the efficacy and safety of extracorporeal shock wave lithotripsy in the treatment of gall bladder stones and to compare in a cost effectiveness analysis these results with the conventional and new surgical techniques.

\section{Methods}

\section{PATIENT SELECTION}

The criteria for selection to this study were those previously described by the Munich Study Group' (Table I) with the exception of the stone characteristics. Gall bladder function was demonstrated by oral cholecystography. Pretreatment investigations included a history and full physical examination, blood chemistry evaluation (clotting parameters, amylase, alkaline phosphatase and aminotransferase concentrations, and a complete blood cell count), abdominal ultrasonography (Ultramark 8, ATL), and oral cholecystography.

From December 1988 to January 1990, 693 patients (601 with radiolucent stones and 92 with a calcified nucleus and/or rim) were treated. The characteristics of both groups are listed in Table II. Stone number and diameter were assessed by radiography. Above three stones the number was not specified because this had no proven value. ${ }^{18}$

The mean (SD) diameter of the stone was $17 \cdot 4$ $(7.5) \mathrm{mm}$ in the case of solitary calculus and $12.6(7 \cdot 7) \mathrm{mm}$ in the case of multiple stones $(p<0.001)$. The influence of possible bias on the success of lithotripsy was assessed by relating

TABLE I Criteria for selection of patients with gall stones for extracorporeal shock wave lithotripsy

\footnotetext{
(1) History of biliary colic

(2) Gall bladder visualisation on oral cholecystography

(3) Identification of the stones and the gall bladder by ultrasonography and successful positioning of the stones in the shock wave focus

(4) Shock wave path that avoids lungs and bone

(5) Absence of acute cholecystitis, cholangitis, biliary obstruction, acute pancreatitis, coagulopathy, medication with anticoagulants or non-steroidal drugs, vascular aneurism or cysts in the shock wave path, pregnancy.
}

TABLE II Patients and stone characteristics

\begin{tabular}{|c|c|c|c|}
\hline & $\begin{array}{l}\text { Radiolucent } \\
(n=601)\end{array}$ & $\begin{array}{l}\text { Radioopaque } \\
(n=92)\end{array}$ & Difference \\
\hline \multicolumn{4}{|l|}{ Patients } \\
\hline Women/men (n) & $457 / 144$ & $69 / 23$ & NS \\
\hline Age, yr, mean (SD) & $51(13)$ & $53(13)$ & NS \\
\hline range & $18-89$ & $36-89$ & \\
\hline median & 50 & 51 & NS \\
\hline BMI, $\mathrm{kg} / \mathrm{m}^{2}$, women & $26 \cdot 48(5 \cdot 16)$ & $26.09(4.95)$ & NS \\
\hline men & $25 \cdot 96(3 \cdot 26)$ & $24 \cdot 86(4 \cdot 13)$ & NS \\
\hline \multicolumn{4}{|c|}{ - } \\
\hline Diameter range, $\mathrm{mm}$ & $5-42$ & $5-36$ & \\
\hline Solitary $(\mathbf{n})$ & 241 & 34 & \\
\hline Mean size, $\mathrm{mm}$ & $17 \cdot 4(7 \cdot 5)$ & $16 \cdot 7(6 \cdot 3)$ & NS \\
\hline$<=20 \mathrm{~mm}(\mathrm{n})$ & 169 & 25 & NS \\
\hline $20-30 \mathrm{~mm}(\mathrm{n})$ & 56 & 8 & NS \\
\hline$>30 \mathrm{~mm}(\mathrm{n})$ & 16 & 2 & NS \\
\hline \multicolumn{4}{|l|}{ Multiple } \\
\hline Mean size, $\mathrm{mm}$ & $12 \cdot 6(7 \cdot 7)$ & $12 \cdot 9(7 \cdot 9)$ & NS \\
\hline $2(n)$ & 83 & 16 & NS \\
\hline $3(\mathrm{n})$ & 56 & 15 & NS \\
\hline$>3(n)$ & 221 & 27 & NS \\
\hline
\end{tabular}

$\mathrm{BMI}=$ body mass index. 
body weight to body length expressed by the body mass index.

\section{LITHOTRIPSY AND ADJUVANT THERAPY WITH BILIARY ACIDS}

All patients were treated with the Piezolith 2300, Wolf, which has a bowl shaped configuration and bears a mosaic of 3000 ceramic elements on its concave surface. The underlying physical principle and the shock wave machine have been described elsewhere. ${ }^{121319}$ The focal area has a width of $3 \mathrm{~mm}$ and a length of $10 \mathrm{~mm}$. The maximal peak pressure in the area was 1200 bar before June 1989 and 1400 bar thereafter, when the upgraded dish array was installed. Ultrasound was used for localisation of the stones, constant monitoring of fragmentation and refocusing of the larger fragments during lithotripsy.

The pulse frequency was set at $1.5 \mathrm{~Hz}$. The number of shock wave discharges administered per session was limited to 3000 , based on experimental studies ${ }^{37}$ and because a higher number of discharges leads to clouding of the gall bladder with resultant suboptimal ultrasonographic visualisation caused by cavitation and fragmentation effects (cloud of dust phenomenon). A maximum of five retreatments were scheduled when fragments larger than $5 \mathrm{~mm}$ were visible by ultrasonography four weeks after the previous lithotripsy session. All the patients were treated in the prone position, with the shock waves entering from the ventral side. The procedure was on an outpatient basis without administration of analgesic or sedative medication. The interval between two consecutive sessions varied between four and six weeks.

Adjuvant chemolitholytic medication was given to obtain complete dissolution of the fragments. Chenodeoxycholic acid and ursodeoxycholic acid, $7.5 \mathrm{mg} / \mathrm{kg}$ body weight, administered daily as a single dose at bedtime, were started 10 days before the first lithotripsy session and continued until the gall bladder was stone free for three months. ${ }^{20}$ Compliance with the oral treatment was assessed by questioning at the control or at follow up.

FOLLOW UP

The predefined outcome for the evaluation of

TABLE III Mean number of sessions for fragmentation and stone free rate in function of number and diameter of the stones

\begin{tabular}{|c|c|c|c|c|c|c|c|}
\hline \multirow[b]{2}{*}{ Stone features } & \multirow[b]{2}{*}{ Patients (n) } & \multirow{2}{*}{$\begin{array}{l}\text { Sessions (mean } \\
(S D) \text { ) }\end{array}$} & \multicolumn{5}{|c|}{$\begin{array}{l}\text { Life table percentages of complete dissolution } \\
\text { after (months) }\end{array}$} \\
\hline & & & 3 & 6 & 9 & 12 & 18 \\
\hline Radiolucent & 601 & $3 \cdot 0(1 \cdot 5)$ & 20 & 41 & 54 & $64 \alpha$ & 78 \\
\hline Solitary & 241 & $2 \cdot 8(1 \cdot 5)$ & 27 & 54 & 67 & $74 \beta$ & 89 \\
\hline$<20 \mathrm{~mm}$ & 169 & $2 \cdot 5(1 \cdot 4)$ & 36 & 61 & 77 & 840 & 91 \\
\hline $20-30 \mathrm{~mm}$ & 56 & $3.4(1.5)$ & 10 & 41 & 42 & 500 & \\
\hline$>30 \mathrm{~mm}$ & 16 & $4 \cdot 1(1 \cdot 1)$ & 0 & 28 & 52 & 520 & \\
\hline 2 stones & 83 & $3 \cdot 3(1 \cdot 3)$ & 12 & 32 & 50 & $65 \beta$ & 81 \\
\hline 3 stones & 56 & $3 \cdot 7(1 \cdot 3)$ & 11 & 30 & 39 & $48 \%$ & 64 \\
\hline$>3$ stones & 221 & $3.3(1.4)$ & 17 & 31 & 44 & $57 \beta$ & 64 \\
\hline Calcified & 92 & $3.6(1.4)$ & 3 & 13 & 27 & $43 \alpha$ & \\
\hline
\end{tabular}

Significantly different:

$\alpha:$ radiolucent versus calcified stones $(\mathrm{p}<0.001)$

(3: solitary versus 2 stones $(\mathrm{p}<0.001)$, solitary versus 3 stones $(\mathrm{p}<0.001)$, and solitary versus more than 3 stones $(\mathrm{p}<0.001)$

(:) stones less than $20 \mathrm{~mm}$ versus stones 20 to $30 \mathrm{~mm}(\mathrm{p}<0.001)$ or stones larger than $30 \mathrm{~mm}(\mathrm{p}<0.01)$. efficacy was the complete disappearance of gall stones, assessed with two consecutive ultrasound examinations (Ultramark 8, annular array, probe $5 \mathrm{Mhz}, \mathrm{ATL}$ ) within three months both in the supine and upright positions. The start of the follow up period was the date of the first lithotripsy session. The stone free date corresponds to the first time the gall bladder was considered to be free of fragments and sludge. The patients were evaluated one month after the first lithotripsy session. If the fragments were larger than $5 \mathrm{~mm}$ a second session was immediately undertaken. If the fragments were smaller than $5 \mathrm{~mm}$ chemolitholytic therapy was continued and the patients were evaluated at three months interval until stone free. This evaluation consisted of a medical history and an ultrasonography of the gall bladder and the common bile duct.

Once stone free the patients were evaluated at six months interval.

\section{STATISTICAL ANALYSIS}

Results are expressed as means (SD) or medians. The statistical significance of differences was assessed with the Student's $t$ test, Wilcoxon's test, the $\chi^{2}$ test or the log-rank test. $p$ Values less than 0.05 were regarded as significant. An actuarial analysis of the probability of disappearance of all fragments was performed according to the life table method of Kaplan and Meier. ${ }^{21}$

\section{Results}

\section{STONE FRAGMENTATION}

In the group of 601 patients with radiolucent lithiasis 1801 lithotripsy sessions were applied. Fragmentation of stones to particles of $5 \mathrm{~mm}$ or less was obtained after $3.0(1.5)$ sessions: 2.8 $(1 \cdot 5)$ sessions for solitary stones and $3.3(1 \cdot 4)$ sessions for multiple stones $(p<0.001)$. For solitary stones the number of sessions for complete fragmentation was significantly different for stones less than $20 \mathrm{~mm}$ versus stones of 20 to $30 \mathrm{~mm}(\mathrm{p}<0.001)$ or stones $>30 \mathrm{~mm}(\mathrm{p}<0.001)$. Only one session was necessary to disintegrate $34 \%$ of solitary stones smaller than $20 \mathrm{~mm}, 11 \%$ of the solitary stones between 21 and $30 \mathrm{~mm}$, and $14 \%$ of the multiple stones. In contrast, none of the single stones larger than $30 \mathrm{~mm}$ was fragmented after the first session. The number of sessions necessary to obtain a complete fragmentation is significantly dependent of the number and size of the stones and the presence of calcifications $(\mathrm{p}<0.001$ versus radiolucent stones) (Table III). Body mass index, sex, and age revealed no statistical significant difference.

\section{STONE CLEARANCE}

Complete stone disappearance calculated by actuarial analysis is shown in Table III and the Figure. The rate of complete clearance increased with time in all groups of patients.

Pairwise comparison of the stone free rate revealed significance between single and multiple stones, lucent versus calcified stones, and solitary stones less than $20 \mathrm{~mm}$ versus solitary stones of 20 to $30 \mathrm{~mm}$ or $<30 \mathrm{~mm}$. Sex, body 


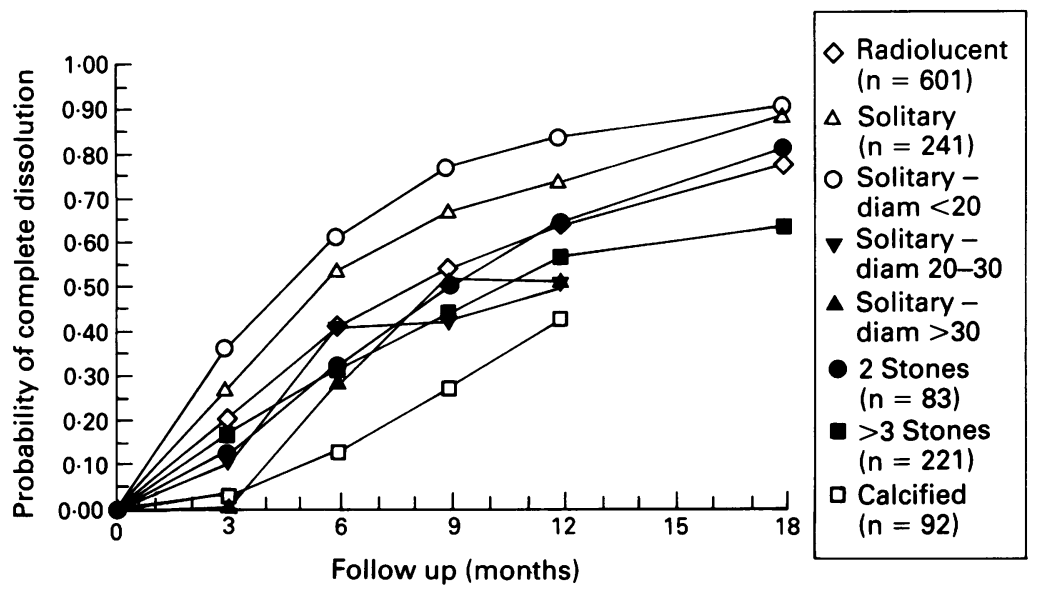

Life table estimates of stone free patients

mass index, and age had no significant influence. Forty seven per cent of the patients with stones with a calcified rim and $33 \%$ of those with a calcified nucleus were stone free after one year.

The stone free patients with radiolucent stones had a median duration of therapy of 124 days ( 95 days for patients with solitary stones less than 20 $\mathrm{mm}$ ) and 216 days for patients with calcified stones.

\section{SIDE EFFECTS}

Lithotripsy caused one or more adverse effects in $50 \%$ of the patients. Minor side effects during the procedure were right upper quadrant discomfort $(7 \%)$ responding to a slight reduction of the intensity, vagal reaction $(1 \%)$, and skin petechiae $(5 \%)$. In one patient an acute abdominal pain syndrome caused by a haematoma in the gall bladder wall necessitated the interruption of the treatment.

In the days or weeks after the lithotripsy $36 \%$ of the patients had attacks of biliary pain. In the majority, pain responded well to minor analgesics. Laboratory and clinical signs of mild pancreatitis occurred in two patients $(0 \cdot 3 \%)$. Five per cent complained of diarrhoea that resolved after a slight reduction of the bile acid medication.

Major side effects resulting in interruption of the treatment were uncontrolled biliary colics in 13 patients, cholecystitis in seven patients and acute pancreatitis in two patients. Twenty five patients were lost to follow up.

\section{FAILURES}

Ninety patients were considered as failures after five sessions and chemolytic therapy for 18 months. In one third of these patients the gall bladder became afunctional. The variables indicating a favourable outcome are a diameter of less than $20 \mathrm{~mm}$, a solitary stone, and the absence of calcifications. The mean age, sex, body mass index, and skin distance were not significantly different.

\section{RECURRENCES}

Three hundred and thirty one stone free patients were evaluated after 12 months: stone recurrence was observed in 19 patients $(5 \cdot 7 \%)$. No statistically significant influence of sex, body mass index, or age was seen at the early recurrence rate. The initial stone mass did not influence the recurrence rate: when the patients with recurrence were analysed with regard to the initial number of stones, the rate of recurrence was $4 \cdot 8 \%$ (eight of 166 ) in patients with solitary stones, $4 \cdot 2 \%$ (two of 48 ) in patients with two stones, and $6.4 \%$ (seven of 110) in patients with more than three stones.

\section{Discussion}

Our results show that extracorporeal shock wave lithotripsy with a piezo electric lithotripter, in combination with chemolitholytic medication for the dissolution of radiolucent gall stones in a functioning gall bladder, is an effective and safe treatment in selected groups of patients. When the number of stones is limited, especially the group of solitary stones with a maximal diameter below $20 \mathrm{~mm}$, the results are excellent with $84 \%$ of patients stone free after one year. Number and diameter as indicators of the total stone mass seem to be important determinants with regard to complete stone disappearance. Our results are comparable with those of the spark gap generator as reported by the Munich group.' In the majority of our patients, however, repeat lithotripsy sessions were necessary to obtain an acceptable fragmentation. With the spark gap system a smaller number of shock waves seems necessary, most patients needing only one session. This difference is probably because of the lower energy per pulse transmitted with the piezo electric system compared with the electrohydraulic one..$^{12} 132223$

We extended the range of indications of the Munich group, and performed extracorporeal lithotripsy combined with oral bile acid dissolution in a group of patients with four to 25 radiolucent stones. As expected, because of the larger stone mass, these patients needed more sessions and complete stone disappearance was slower: the success rate was $57 \%$ at one year.

In patients with partially calcified stones the success rate was lower. Forty seven per cent of those with a calcified rim and $33 \%$ of those with a calcified nucleus were, however, stone free after one year. Lithotripsy with the piezo electric generator Wolf 2300 is well tolerated, only $7 \%$ experienced local pain of moderate intensity during or immediately after the procedure. Indeed, the piezo electric generator has a high pressure gain which implies that the peak pressure at the skin, where the beam enters the patient, is rather low. ${ }^{22} 23$ This is why it can be performed on an outpatient basis, without administration of analgesic or sedative medication and this represents an important clinical advantage over the electrohydraulic technique of shock wave generation.

Good visualisation of the stones during lithotripsy is essential to optimise fragmentation, especially with the Wolf 2300 lithotriptor, the focusing area being small. A suboptimal ultrasonographic localisation could explain less satisfactory results obtained in some other centres. ${ }^{3}$ Therefore, previous ultrasound experience is recommended before starting with the Piezolith 2300 . 
The incidence of recurrent biliary colic is rather high. In the majority of patients, however, the pain is of short duration and responds well to spasmolytic medication or minor analgesics. Because only symptomatic patients were treated, it is difficult to distinguish biliary pain which occurs as part of the natural course of the disease from that caused by lithotripsy. Other significant side effects were uncommon.

One third of the failures are caused by the development of an afunctional gall bladder which precludes the dissolution of the remaining small fragments.

The long term success of management of gall stones disease not involving the removal of the gall bladder is, however, confronted with the risk of gall stone recurrence as the defects leading to primary gall stone formation often persist. ${ }^{23-25}$ In our patients stone recurrence was $5 \cdot 7 \%$ at one year which is somewhat lower than the recurrence rate observed by the Munich group: $11 \%$ at one year and $15 \%$ at two years. ${ }^{27}$ These percentages are lower than those reported in postdissolution trials. ${ }^{28}{ }^{29}$ To our surprise, we did not observe any influence of age, sex, and body mass index upon the success rate and the recurrence rate; even the initial number of stones apparently did not influence the recurrence rate, which is in contradiction with the postdissolution experience where the recurrence was higher in patients with multiple stones than with solitary stones. ${ }^{28}$ Lasting success of extracorporeal shock wave lithotripsy for biliary stones will depend on advances in secondary prevention.

Success of extracorporeal shock wave lithotripsy was mitigated by the increasing importance of laparoscopic cholecystectomy, ${ }^{17-30}$ and in comparing new techniques projected costs must be analysed. In our country each lithotripsy session costs US\$315 (£185); a medical treatment with $500 \mathrm{mg}$ ursodeoxycholic acid and $500 \mathrm{mg}$ chenodeoxycholic acid daily during one year costs US\$886 ( $\$ 517)$. In estimating the cost of extracorporeal shock wave lithotripsy, the failures and recurrences that eventually need surgery must be taken into consideration.

Extracorporeal shock wave lithotripsy for solitary stones with its $85 \%$ effectiveness at one year, two sessions of extracorporeal shock wave lithotripsy, 15\% failures and an estimated 30\% recurrences in the long term (assuming that only half of them become symptomatic and therefore need treatment) will cost US\$1970 (£1150).

For multiple stones, however, with at least three sessions, and $40 \%$ failures, the expected cost is US\$2695 ( $£ 1570$ ).

In our country the cost of a conventional cholecystectomy is estimated at US $\$ 2400$ (£1400), the inability to work not taken into consideration.

Because of its shorter hospital stay, the cost to the community of laparoscopic cholecystectomy (with a 5\% morbidity) can be estimated at US $\$ 1570$ ( $£ 920$ ). Early resumption of normal activities is expected with this technique.

The cost of extracorporeal shock wave lithotripsy is strongly influenced by the stone number, volume, and characteristics. Optimal results with least expenditure are obtained in patients with radiolucent solitary stones, less than $2 \mathrm{~cm}$ diameter, with a total cost comparing favourably with the conventional cholecystectomy.

Indiscriminate patient selection is in our opinion unwanted and extracorporeal shock wave lithotripsy should be largely restricted to patients with solitary stones, as careful patient selection is the key to obtaining optimal results with the least expenditure. This cost effectiveness analysis, however, suggests that overall laparoscopic cholecystectomy is the most economic therapeutic approach to the patient with symptomatic gall bladder stones.

We are grateful to Dirk Leplae, Chris Van Imschoot, and Philippe Van De Wiele for their technical assistance and Annette Verbist for her secretarial assistance.

1 Sackmann M, Delius M, Sauerbruch T, Holl J, Weber W, Ippisch E, et al. Shock-wave lithotripsy of gallbladder stones. The first 175 patients. N Englf Med 1988; 318: 393 7.

2 Sackmann M, Pauletzki J, Sauerbruch T, Holl J, Schelling G, Paumgartner G. The Munich gallbladder lithotripsy study. Results of the first

3 Ell C, Kerzel W, Schneider H, Benninger J, Wirtz P, Domschke W, et al. Piezoelectric lithotripsy: stone disintegration and follow-up results in patients with symptomatic gallbladder stones. Gastroenterology 1990; 99: 143944

4 Schoenfield L, Berci G, Carnovale R. The effect of ursodiol on the efficacy and safety of extracorporeal shock-wave lithotripsy of gallstones. The Dornier national biliary lithotripsy study. N Engl f Med 1990; 323: 1239-45.

5 Ponchon T, Barkun AN, Pujol B, Mestas JL, Lambert R. Gallstone disappearance after extracorporeal lithotripsy and oral bile acid dissolution. Gastroenterology 1989; 97: 457-63.

6 Ell C, Kerzel W, Günter W, Heyder N, Rödl W, Flügel H, et al. Piezoelektrische lithotripsie von Gallensteinen. Erste klinische Erfahrungen. Dtsch Med Wochenschr 1988; 113. klinische

7 Ell C, Kerzel W, Heyder N, Becker V, Hermaneck P Domschke W. Piezoelectric lithotripsy of gallstones. Lance 1987; ii: 1149-50.

8 Ell C, Kerzel W, Heyder N, Gunther E, Domschke W. Piezoelectric lithotripsy of gallstones: experimental studies and preliminary clinical results. In: Ferruci J, Delius $M$,
Burhenne HJ, eds. Biliary lithotripsy. Chicago: Year Book Medical Publishers, 1989: 103-8.

9 Delmont JP, Magnier M, Mosnier H, Moreaus J, Guivarc'h M, Sokolowsky S, et al. Results of gallstones lithotripsy in 212 patients using the EDAP LT-01. In: Ferruci J, Delius M, Burhenne HJ, eds. Biliary lithotripsy. Chicago: Year M, Burhenne HJ, eds. Biliary lithotrip

10 Riemann J, Adamek H, Weber J. Piezoelectric lithotripsy in the treatment of symptomatic gallstone patients. $\mathcal{F}$ Clin Gastroenterol 1991; 13: 395-400.

11 Burnett D, Ertan A, Jones R, O'Leary JP, Mackie R, Robinson JE, et al. Use of external shock-wave lithotrips and adjuvant ursodiol for treatment of radiolucent gallstones. A national multicenter study. Dig Dis Sci 1989; 34 $1011-5$

12 Schachler R, Bird N, Sauerbruch T, Frost E, Sackmann M, Paumgartner $\mathrm{G}$, et al. Extracorporeal shock-wave lithotripsy of gallstones: an in vitro comparison between an electrohydraulic and a piezo-ceramic device. Gut 1991; 32: 312-5.

13 Schneider T, Fromm M, Ott R, Janowitz P, Swobodnik W, Neuhaus $\mathrm{H}$, et al. In vitro fragmentation of gallstones: comparison of electro-hydraulic, electromagnetic and comparison of electro-hydraulic, electromagnetic and piezoelecti

14 Perissat J, Collet D, Belliard R. Gallstones: laparoscopic treatment, intracorporeal lithotripsy followed by cholecystostomy or cholecystectomy - a personal technique. Endoscopy 1989; 21: 373-4.

15 Dubois F, Icard P, Berthelot G, Levard H. Coelioscopic cholecystectomy: preliminary report of 36 cases. Ann Sur 1990; 211: 60-2.

16 Reddick E, Olsen D. Laparoscopic laser cholecystectomy: comparison with mini-lap cholecystectomy. Surg Endos 1989; 3: 131-3.

17 Meyers W, and the Southern Surgeons Club. A prospective analysis of 1518 laparoscopic cholecystectomies. $N E n g l$ 7 Med 1991; 324: 1073-8.

18 Brink J, Simeone J, Mueller P, Saini S, Tung G, Spell N, et al Routine sonographic techniques fail to quantify gallstone

19 Ell C, Kerzel W, Rödl W, Langer H, Heyder N, Foerster E, et al. Fragmentation of biliary calculi by means of extracorporeally generated piezoelectric shockwaves. Dig Dis Sc 1989; 34: 1006-10.

20 Podda M, Zuin M, Batterzati PM, Ghezzi C, Fazio C Dioguardi ML. Efficacy and safety of a combination of chenodeoxycholic acid and ursodeoxycholic acid for gallstone dissolution: a comparison with ursodeoxycholic acid alone. Gastroenterology 1989; 96: 222-9. 
21 Kaplan EL, Meier P. Nonparametric estimation from incomplete observations. $\mathcal{f}$ Am Stat Assoc 1985; 53: 45781 .

22 Coleman AJ, Saunders JE. Shock-wave generators in extracorporeal shock-wave lithotripsy. In: Ferruci J, Burhenn HJ, eds. Biliary lithotripsy. Chicago: Year Book Medical Publishers, 1989: 17-22.

23 Coleman AJ, Saunders JE. A survey of the acoustic output of commercial extracorporeal shock-wave lithotripters. Ultrasound Med Biol 1989; 15: 213-27.

24 Way L. Changing therapy for gallstone disease. $N$ Engl f Med 1990; 323: 1273-4.

25 Katz $S$ and the ACG Committee on FDA-related matters Biliary lithotripsy: more questions than answers. $\mathrm{Am} \mathscr{f}$ Gastroenterol 1990; 85: 497-509.
26 Flick A. Restraint urged for biliary lithotripsy. Dig Dis Sci 1990; 35: 916-7.

27 Sackmann M, Ippisch E, Sauerbruch T, Holl J, Brendel W, Paumgartner G. Early gallstone recurrence rate after successful shock-wave therapy. Gastroenterology 1990; 98: 392-6

28 Villanova N, Bazzoli F, Taroni F, Frabboni R, Mazzella G, Festi $\mathrm{D}$, et al. Gallstone recurrence after successful oral bile acid treatment. Gastroenterology 1989; 97: 726-31.

29 Lanzini A, Jazriwi RP, Kupfer RM, Maudgal DP, Joseph AE, Northfield TC. Gallstone recurrence after medical dissolution: an overestimated threat? F Hepatol 1986; 3: 241-6.

30 Reddick EJ, Miller TA. Laparoscopic cholecystectomy: passing fancy or legitimate treatment option. Gastroenterology
1990;99: 1527-9. 